\title{
Rhodotorula glutinis - potential source of lipids, carotenoids, and enzymes for use in industries
}

\author{
Anna M. Kot $^{1}$ • Stanisław Blażejak ${ }^{1}$ - Agnieszka Kurcz ${ }^{1}$. \\ Iwona Gientka $^{1}$ • Marek Kieliszek ${ }^{1}$
}

Received: 15 March 2016/Revised: 29 April 2016 / Accepted: 2 May 2016/Published online: 21 May 2016

(C) The Author(s) 2016. This article is published with open access at Springerlink.com

\begin{abstract}
Rhodotorula glutinis is capable of synthesizing numerous valuable compounds with a wide industrial usage. Biomass of this yeast constitutes sources of microbiological oils, and the whole pool of fatty acids is dominated by oleic, linoleic, and palmitic acid. Due to its composition, the lipids may be useful as a source for the production of the so-called third-generation biodiesel. These yeasts are also capable of synthesizing carotenoids such as $\beta$-carotene, torulene, and torularhodin. Due to their health-promoting characteristics, carotenoids are commonly used in the cosmetic, pharmaceutical, and food industries. They are also used as additives in fodders for livestock, fish, and crustaceans. A significant characteristic of $R$. glutinis is its capability to produce numerous enzymes, in particular, phenylalanine ammonia lyase (PAL). This enzyme is used in the food industry in the production of L-phenylalanine that constitutes the substrate for the synthesis of aspartame - a sweetener commonly used in the food industry.
\end{abstract}

Keywords Oleaginous yeast $\cdot \beta$-Carotene $\cdot$ Torulene .

Torularhodin $\cdot$ Phenylalanine ammonia-lyase

\section{Introduction}

Until recently, the yeasts of the genus Rhodotorula were primarily considered to be saprophytes that spoil food. In recent

Anna M. Kot

anna_kot@sggw.pl

1 Department of Biotechnology, Microbiology and Food Evaluation, Faculty of Food Sciences, Warsaw University of Life Sciences, Nowoursynowska 159C, 02-776 Warsaw, Poland times, a large number of studies have been published on the biotechnological uses of these yeasts, which suggest that they may constitute important group of microorganisms that might be of importance in industries in the future. Rhodotorula glutinis is considered to be the typical species of this genus. These yeasts are capable of synthesizing numerous metabolites useful in industries, such as lipids, carotenoids, and enzymes. Their clear advantage is their capacity to grow and synthesize metabolites on substrates containing different industrial waste raw materials, which considerably elevates the economic profitability of biotechnological processes. This study presents a literature review on the possibility to obtain microbiological lipids, carotenoids, and enzymes from $R$. glutinis biomass and their potential use in industries. Moreover, the pathways of lipids and carotenoid biosynthesis and the influence of selected environmental factors on the efficiency of these processes are described.

\section{History, taxonomy, morphology, and physiology of R. glutinis}

Over the years, the asexually reproducing, colored yeasts have been assigned to numerous genera, such as Torula, Mycotorula, Torulopsis, Cryptococcus, and even Saccharomyces. Francis Charles Harrison, a Canadian microbiologist, who worked on yeasts found in regional cheeses in the 1930s, was the first one to use the name Rhodotorula (Barnett 2004). The genus name originates from the word rhodos (red in Greek) and torula (feminine diminutive form of the Neo-Latin torus-bulge) (Krzyściak et al. 2007).

Rhodotorula glutinis is considered to be a typical species of this genus, and it was described by Georg Fresenius in 1850 . The yeasts were isolated from the cream of sour milk and named Cryptococcus glutinis at that time (Barnett 2004). 
R. glutinis is included in the order Sporidiobolales, class Microbotryomycetes, and phylum Basidiomycota in the Fungi kingdom. Integrated Taxonomic Information System provides three synonyms of the Latin name of Rhodotorula glutinis: $R$. rufula, $R$. glutinis var. rubescens, and $R$. gracilis (ITIS Standard 2016). The following varieties are distinguished within the species: Rhodotorula glutinis (Fresenius) var. glutinis, Rhodotorula glutinis var. dairenensis (yeast isolated in 1922 by Saito from air) (Fell and Statzell-Tallman 1998), and Rhodotorula glutinis var. salinaria (yeast isolated in 1969 from salt) (Hirosawa and Takada 1969).

The majority of the yeasts included in the species are mesophilic, although some of them thrive under lower temperatures, and aerobic organisms. The cells are spherical, ellipsoidal, or elongated in shape. $R$. glutinis reproduce asexually by multilateral or polar budding; certain strains form residual pseudomycelium (Fell and Statzell-Tallman 1998).

These yeasts are capable of using many compounds as sources of carbon. They include glucose, galactose, sucrose, maltose, trehalose, ethanol, glycerol, and hexadecane. A characteristic feature of this genus is its lack of capacity to perform sugar fermentation. The cells produce urease and Q-10 coenzyme. They can grow in the presence of $10 \% \mathrm{NaCl}$, but they do not tolerate glucose concentration above $50 \%$ (Fell and Statzell-Tallman 1998).

R. glutinis colonies that grow on permanent malt medium exhibit characteristic coloration that depends on the type of strain and growth conditions. They can be of creamy, yellow, salmon, pink, orange, coral, and blood red in color. In liquid media, they grow in the form of orange ring or sediment (Fell and Statzell-Tallman 1998; Hernández-Almanza et al. 2014). The colored pigmentation of the cells is due to the production of large amounts of carotenoids, which are responsible for protecting the cells against the effect of singlet oxygen and excessive radiation of visible and UV light spectrum (Hernández-Almanza et al. 2014).

Rhodotorula yeasts occur in common in the environment. They are isolated from air, soil, grass, lakes, oceans, food (i.e., milk, fruit juices), human skin, and feces (Wirth and Goldani 2012). The majority of the representatives of the genus do not exhibit pathogenic properties, although opportunistic pathogens are found among them, which cause dermatophytoses, and are referred to as rhodotorulosis. The most common etiological factors of these infections are the strains of the species Rhodotorula mucilaginosa (Biswas et al. 2001).

\section{Lipid biosynthesis by Rhodotorula glutinis}

In recent years, there has been an increased interest in developing new methods to obtain lipids from these yeasts. One such method includes the production of microbiological lipids, referred to as SCO in the literature (single cell oil) (Beopoulos and Nicaud 2012). In comparison to the production of vegetable and animal fats, this method is independent of climate, season, and geographical position of a country. Production cycle is short, thanks to the rapid growth rate exhibited by the microorganisms (Santos et al. 2013). Microbiological lipids can be used as food additives, diet supplements, and substitutions for precious fats. Microbiological oils can also be used as substrates in the so-called third-generation biodiesel production (Li et al. 2008; Papanikolaou and Aggelis 2011b; Papanikolaou et al. 2001, 2003; Ratledge and Cohen 2008).

The yeast Rhodotorula glutinis belongs to the group of oleaginous microorganisms (Table 1), which are defined as those that are capable of producing and accumulating over $20 \%$ of lipids in dry cellular substance (Ratledge and Cohen 2008). Fat is stored in the lipid bodies (Ham and Rhee 1998), whose structure is similar in all oleaginous yeasts. The core consists of backup hydrophobic compounds (such as triacylglycerols, free fatty acids, and sterols), and it is surrounded by a layer of phospholipids bound to proteins (Fickers et al. 2005). In these yeasts, the lipid bodies consist of neutral lipids in the form of triglycerides, and the composition of phospholipids differs from this composition in other cellular organelles. This stems from the fact that they primarily consist of phosphatidylcholine (38.6 \%) and phosphatidylserine (43\%) (Ham and Rhee 1998).

\section{Mechanism of lipid biosynthesis}

In yeast cells, lipids may be accumulate via two pathways: de novo (from acetyl-CoA and malonyl-CoA molecules) and ex novo (Beopoulos and Nicaud 2012). In the de novo method, saccharides or glycerol constitutes the substrates for lipids production (Papanikolaou and Aggelis 2011a), whereas in the ex novo biosynthesis, hydrophobic compounds serve as the substrates (Beopoulos et al. 2009). Culture media primarily containing glucose, sucrose, glycerol, and sugar waste raw materials such as molasses and different hydrolysates are used as sources of carbon for the production of lipids by the yeast Rhodotorula glutinis (Table 1).

In the de novo synthesis, the overproduction of intracellular lipids occurs after the depletion of nitrogen compounds from the culture environment, which is related to the activation of AMP deaminase. This enzyme catalyzes the decomposition of AMP to IMP and $\mathrm{NH}_{4}{ }^{+}$ions, which constitute the additional source of nitrogen. A decrease in the adenosine monophosphate level disturbs the course of the Krebs cycle because this compound activates isocitrate dehydrogenase that catalyzes the transformation of isocitrate to $\alpha$-ketoglutarate. Under such conditions, mitochondrion accumulates isocitrate that remains in balance with citrate, thanks to the activity of aconitase. After attaining a critical concentration, citric acid is transported from mitochondrion to the cytoplasm, where it is 


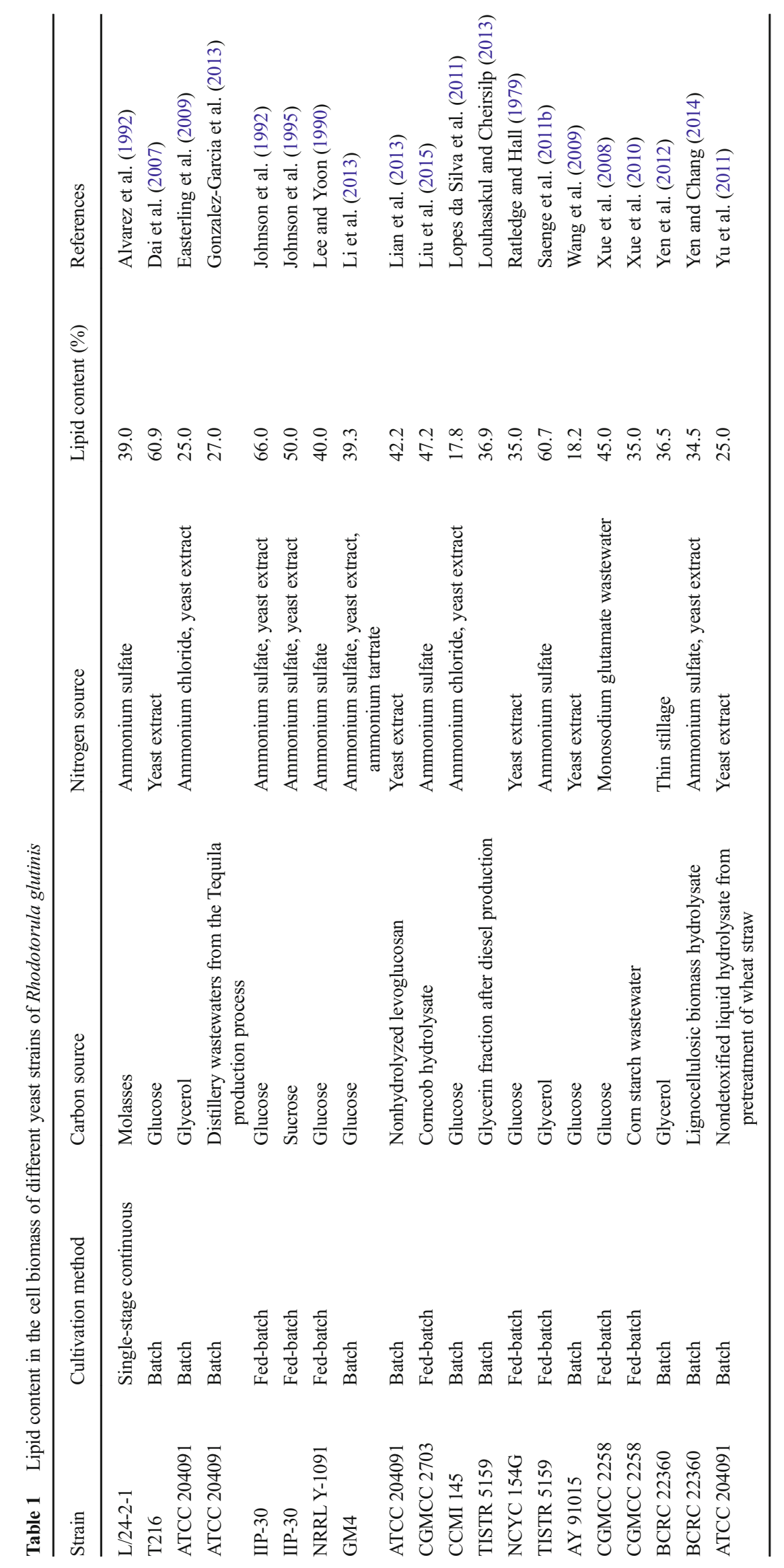


split by ATP-citrate lyase to acetyl-CoA and oxaloacetate. The first stage of fatty acid synthesis is carboxylation of acetyl$\mathrm{CoA}$, as a result of which malonyl $\mathrm{CoA}$ is produced. Then, a sequence of enzymatic reactions occurs, catalyzed by the complex of fatty acid synthase (FAS). The fatty acids produced can then be included in the pathway of triacylglycerol synthesis (Papanikolaou and Aggelis 2011a).

\section{Factors affecting on the biosynthesis of intracellular lipids}

The biosynthesis of intracellular lipids by Rhodotorula glutinis is influenced by many factors. A significant role has the appropriate high $\mathrm{C} / \mathrm{N}$ molar ratio in the culture medium. Saenge et al. (2011b) used glycerol as a carbon source for the production of lipids by $R$. glutinis TISTR 5159 , and the $\mathrm{C} / \mathrm{N}$ ratio in the medium remained in the range $35-85$. The results obtained by the authors suggested that the optimal addition of glycerol for the production of the yeast biomass amounts to $8.5 \%(\mathrm{C} / \mathrm{N} 60)$. When the glycerol content was increased to $9.5 \%(\mathrm{C} / \mathrm{N} 85)$, highest lipid content was observed (approx. $42 \%$ ). Then, yeast was cultivated on the medium with an initial $\mathrm{C} / \mathrm{N}$ ratio of 85 in a biofermenter tank. The highest lipid content $(60.7 \%)$ was obtained after $72 \mathrm{~h}$, and it contained mainly oleic acid (45.75\%) and linoleic acid (17.92\%). The lipid yield after this time was $6.10 \mathrm{~g} / \mathrm{L}$.

The process of lipid biosynthesis by $R$. glutinis also depends on the type of carbon source found in the culture medium. Easterling et al. (2009) cultivated R. glutinis ATCC 204091 on media containing glucose, xylose, glycerol, glucose + xylose, glucose + glycerol, and xylose + glycerol. These compounds were added to the medium in such amounts that the initial $\mathrm{C} / \mathrm{N}$ molar ratio amounted to 10 . The intracellular lipids content varied, depending on the carbon source, and amounted from 10 (glucose and xylose) to $34 \%$ (glucose + glycerol).

The acidity of the culture medium also has considerable effect on the lipids biosynthesis. Johnson et al. (1992) determined its influence during the cultivation of oleaginous strain of $R$. glutinis IIP-30 on medium containing $3 \%$ of glucose as the source of carbon, $0.2 \%$ of ammonium sulfate and $0.1 \%$ of yeast extract as nitrogen sources. The highest lipid content $(66 \%)$ was obtained on the medium at $\mathrm{pH} 4.0$, whereas at $\mathrm{pH} 3.0,5.0$, and 6.0 , its content amounted to 12,48 , and $44 \%$, respectively.

The presence of dissolved oxygen in the culture medium constitutes another factor that determines the biosynthesis of intracellular lipids by yeasts. Yen and Zhang (2011a) observed that increasing the content of dissolved oxygen in the medium decreased the total amount of lipids produced in R. glutinis BCRC 22,360. When the oxygen level was established at $25 \pm 10 \%$, the lipid content in the biomass was $62 \%$, whereas when the level was increased to $60 \pm 10 \%$, it decreased to $52 \%$.

\section{Lipid biosynthesis from waste substrates}

Studies showed that it is a possible to obtain microbial oils in media containing different waste products. Processes conducted on such substrates greatly increase the economic costeffectiveness of SCO production and enable partial biodegradation of problematic industrial waste (Almazan et al. 1981; Alvarez et al. 1992; Cheirsilp et al. 2011, 2012; GonzalezGarcia et al. 2013; Lian et al. 2013; Liu et al. 2015; Louhasakul and Cheirsilp 2013; Saenge et al. 2011b; Schneider et al. 2013; Xue et al. 2008, 2010; Yu et al. 2011; Yen et al. 2012; Yen and Chang 2014).

Xue et al. (2008) used wastewater obtained from the production of monosodium glutamate as the nitrogen source. The medium was supplemented with glucose and $R$. glutinis was cultivated for $120 \mathrm{~h}$. The obtained cellular biomass yield and lipid content amounted to $25 \mathrm{~g}_{\text {d.w. }} / \mathrm{L}$ and $20 \%$, respectively. As a result of the process, a $45 \%$ reduction of the chemicaloxygen demand indicator was obtained. Other authors (Gonzalez-Garcia et al. 2013) cultivated R. glutinis ATCC 204091 on medium prepared from distillery wastewater obtained from the production of tequila. After $144 \mathrm{~h}$ of the process, the lipid content amounted to $27 \%$ and the COD index decreased by $84.44 \%$. Xue et al. (2010) used wastewater from starch production as culture medium. After $60 \mathrm{~h}$ of cultivation in 5-L biofermenter tank, the amount of cellular biomass obtained exceeded $60 \mathrm{~g}_{\text {d.w. }} / \mathrm{L}$ and the lipids content amounted to $30 \%$. At the stage of the experiment, the culture was conducted in a 300-L biofermenter tank, using the same waste type as the culture medium, without prior sterilization and regulation of active acidity. The cellular biomass yield amounted to $40 \mathrm{~g} /$ $\mathrm{L}$, and the participation of lipid remained at the level of $35 \%$, already after $30-40 \mathrm{~h}$ of the culture. After this time, an $80 \%$ reduction in the chemical-oxygen demand indicator of the culture medium was noted. Yen et al. (2012) cultivated $R$. glutinis BCRC 22360 on medium containing crude glycerol obtained during biodiesel production and thin stillage collected from the brewing company. The process was carried out in a 5-L biofermenter tank, and the biomass yield and lipid content in the cellular biomass amounted to $14.8 \mathrm{~g}_{\text {d.w. }} / \mathrm{L}$ and $36.5 \%$, respectively. Moreover, a study was conducted by Yen and Chang (2014) with the use of the same yeast strain on medium containing waste formed after the production of cellulose and hemicellulose (lignocellulosic biomass hydrolyzate (LCB)). Lipid content amounted to $34.3 \%$ after cultivation on medium containing $6 \%$ of reducing sugars.

Cheirsilp et al. (2011) cultivated a mixed culture of R. glutinis TISTR 5159 yeast and Chlorella vulgaris TISTR 8261 microalgae on media containing waste obtained from seafood processing plant and molasses obtained from sugar cane plant. It was determined that pure $R$. glutinis TISTR 5159 yeast culture exhibited a more rapid growth rate than the Chlorella vulgaris monoculture. However, in the case of a 
mixed culture, increased biomass yield and fat biosynthesis efficiency were observed compared to the separate culture of these microorganisms. This regularity could be the result of the syngergistic effect of these strains, consisting in the fact that the microalgae produced oxygen absorbed by yeasts, which biosynthesized lipids at the same time. The highest biomass yield $\left(4.63 \mathrm{~g}_{\text {d.w. }} / \mathrm{L}\right)$ and efficiency of microbiological oils $(2.88 \mathrm{~g} / \mathrm{L})$ were obtained after 5 days of culture on medium with $1 \%$ addition of molasses, under 5.0 klux light intensity.

\section{Fatty acid profile of lipids synthesized by $R$. glutinis and its uses}

Lipids synthesized by $R$. glutinis contain primarily palmitic (C16:0), oleic (C18:1), linoleic (C18:2), and linolenic acids (C18:3). The main fatty acid included in the lipids synthesized by $R$. glutinis is oleic acid, and its percentage in the total pool of fatty acids may exceed above $60 \%$. The linoleic acid percentage ranges from above 5 to $25 \%$, and palmitic acid constitutes on average of above 10-30\%. Low percentage of the fat synthesized by these yeasts is characteristic of stearic acid (to $10 \%$ ); however, in certain strains, its content may reach up to $25 \%$ (Table 2).

Profile of fatty acids synthesized by the $R$. glutinis primarily depends on the yeast strain and composition of the culture medium (Zhang et al. 2011) (Table 2). However, the composition of the lipids can also be adjusted by modifying the molar ratio $\mathrm{C} / \mathrm{N}$ in the culture medium (Braunwald et al. 2013), temperature of cultivation (Suutari et al. 1990), and by genetic modification of yeast (Shichang et al. 2013). A significant impact on the profile of fatty acids synthesized by the $R$. glutinis yeast has also time of cultivation (Mast et al. 2014; Zhang et al. 2011). Zhang et al. (2011) noted that increasing the time of cultivation $R$. glutinis ATCC 15,125 yeast increased content of unsaturated fatty acids, from $46(0 \mathrm{~h})$ to $63.1 \%(233 \mathrm{~h})$. At this time, oleic and linoleic acids content increased from 26.9 and 8.5 to 43.8 and $12.7 \%$, respectively.

Significant impact on the profile of fatty acids has also the molar ratio of carbon to nitrogen $(\mathrm{C} / \mathrm{N})$ in the culture medium. Braunwald et al. (2013) observed that the content of saturated fatty acids C16:0 and C18:0 in the biomass of R. glutinis ATCC 15125 was the lowest after cultivation in the medium with the initial C/N 20. Also, in this case, authors observed the highest concentration of oleic C18:1 (39.9-44.4\%) and linoleic acids C18:2 (31.2-42.3\%). In contrast, the highest content of linolenic acid (6.54-7.35\%) was determined in yeast cells cultivated in media with a high $\mathrm{C} / \mathrm{N}$ ratio equal 70 and 120 , while in the medium with the initial C/N 20 was significantly lower (3.67-3.97\%).

Composition of fatty acids synthesized by $R$. glutinis is also dependent on temperature of cultivation. Changes in the proportions of fatty acids are one of the factors of yeast adaptation to life in environments with different temperatures. At a lower temperature, yeasts synthesize more unsaturated fatty acids, which is associated with changes of the cell membranes (Zlatanov et al. 2010). Suuta et al. (1990) found that the Rhodosporidium toruloides VTT-C-132 82 (teleomorph stages of $R$. glutinis) synthesized the largest amount of linoleic acid (approx. $22 \%$ ) at $10{ }^{\circ} \mathrm{C}$. The content of this acid after cultivation at $40{ }^{\circ} \mathrm{C}$ was only approx. $10 \%$. Lipids synthesized by $R$. glutinis can be also enriched in linoleic acid through genetic modification. Shichang et al. (2013) used for this purpose implantation of nitrogen ions. The obtained mutant D30 synthesized almost 3-fold more linoleic acid (27\%) compared to the parental strain R. glutinis 31,596 $(9.93 \%)$, while significantly reduced oleic acid (from 61.8 to $49.3 \%$ ) and palmitic acid (from 5.66 to $11.0 \%$ ).

Due to the participation of individual fatty acids in the lipids synthesized by $R$. glutinis, researchers have indicated the possibility of using these yeasts as a source of substrates for biodiesel production (Dai et al. 2007; Liu et al. 2015; Mast et al. 2014; Saenge et al. 2011a; Schneider et al. 2013; Xue et al. 2010; Yen and Zhang 2011b; Zhang et al. 2011). Biodiesel is defined as a fuel consisting of fatty acid monoalkyl long-chain esters, most commonly methyl esters. The ecological aspect of the fuel explains the considerable growth in the interest its usage. Biodiesel is fully renewable and biodegradable. Its usage favorably influences the state of the environment, primarily because of its decreased emission of greenhouse gasses to the atmosphere (Adamczak et al. 2009). Depending on the type of raw material used for its production, biofuel is classified as three types and are as follows: first-generation biodiesel produced from plant oils such as rapeseed and soybean oil, second-generation biodiesel produced from oily nonfood raw materials (e.g., Jatropha), and third-generation biodiesel produced from the lipids of microbiological origin (Schneider et al. 2013). Currently, thirdgeneration biodiesel is not produced at industrial level because their microbiological synthesis is expensive (Zhang et al. 2014). Therefore, further study should concentrate on lowering its production costs. This aim can be achieved by genetically modifying yeasts in order to increase their biosynthetic efficiency or by using waste products as components of the culture media (Kot et al. 2015).

\section{Carotenoid biosynthesis by Rhodotorula glutinis}

Carotenoids belong to the group of natural pigments found in fruits, vegetables, fish, eggs, and oil (Rao and Rao 2007). Additionally, they are synthesized by certain microbes, including R. glutinis yeast (Table 3) (Perrier et al. 1995). They are characterized by yellow, orange, or red coloration. Until now, approximately 750 compounds of this type have been 


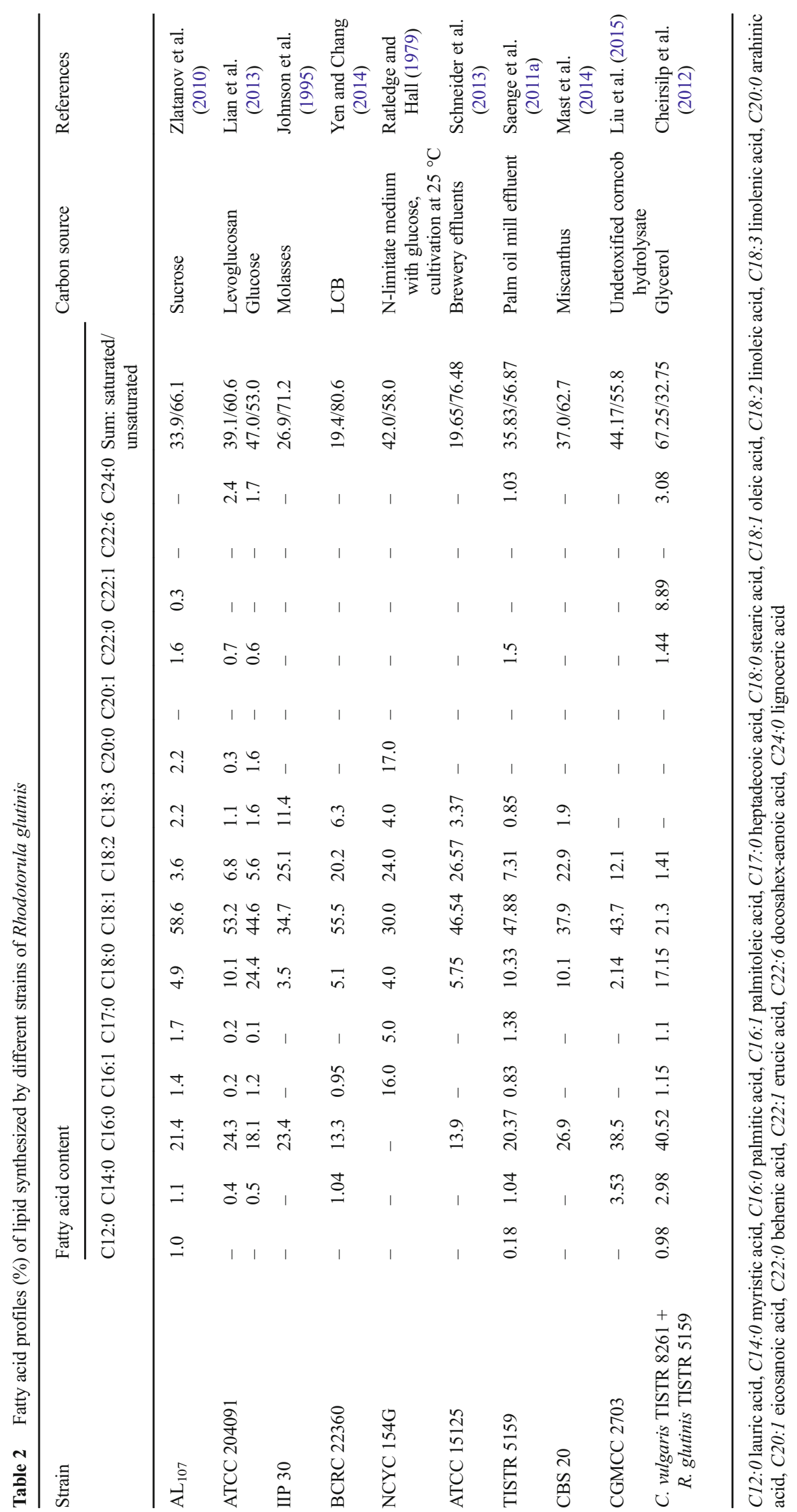


Table 3 Efficiency of carotenoid biosynthesis by different strains of Rhodotorula glutinis

\begin{tabular}{|c|c|c|c|c|c|}
\hline Strain & Cultivation method & Carbon source & Nitrogen source & $\begin{array}{l}\text { Carotenoid biosynthesis } \\
\text { efficiency }(\mathrm{mg} / \mathrm{L})\end{array}$ & References \\
\hline \multirow[t]{3}{*}{ NCIM 3353} & \multirow[t]{3}{*}{ Batch } & \multirow[t]{3}{*}{ Molasses } & Malt extract & 24.1 & \multirow[t]{3}{*}{ Bhosale and Gadre (2001a) } \\
\hline & & & Yeast extract & 42.6 & \\
\hline & & & Ammonium sulfate & 14.4 & \\
\hline DBVPG 3853 & Batch & $\begin{array}{l}\text { Concentrated rectified } \\
\text { grape must }\end{array}$ & & 5.95 & Buzzini and Martini (1999) \\
\hline DBVPG 3853 & Batch & $\begin{array}{l}\text { Concentrated rectified } \\
\text { grape must }\end{array}$ & Yeast extract & $6.97^{\mathrm{a}}$ & Buzzini (2000) \\
\hline $\mathrm{C} 2.5 \mathrm{t} 1$ & Batch & Glycerol & Yeast extract & 14.92 & Cutzu et al. (2013) \\
\hline CCY 20-2-26 & Fed-batch & Glucose & Ammonium sulfate & 23.34 & Marova et al. (2010) \\
\hline MT-5 & Batch & $\begin{array}{l}\text { Detoxified loquat } \\
\text { kernel extract }\end{array}$ & Peptone & 72.36 & Taskin and Erdal (2010) \\
\hline MT-5 & Batch & Glucose & $\begin{array}{l}\text { Waste chicken feathers, } \\
\text { yeast extract }\end{array}$ & 92 & Taskin et al. (2011) \\
\hline TISTR & Batch & Sweet potato extract & Dried mung bean flour & 3.48 & Tinoi et al. (2005) \\
\hline
\end{tabular}

${ }^{\text {a }}$ Only $\beta$-carotene content provided

identified (Maoka 2011), out of which 50 compounds exhibit provitamin A activity (Fraser and Bramley 2004). Humans are unable to biosynthesize carotenoids, and therefore, they must be supplied with diet (Woodside et al. 2015). These compounds are highly soluble in fats but they do not dissolve in water. Carotenoids exhibit health promoting activity toward human body. Thanks to their antioxidant properties, they protect the skin against the UV light. They possess antioxidative effect against free radicals as well as reactive oxygen species. They strengthen the immune system and accelerate wound healing. Some carotenoids may be protective in eye disease because they constitute vitamin A precursors (Krinsky and Johnson 2005; Rao and Rao 2007).

Carotenoids are used in various industrial sectors as components of cosmetics (Anunciato and da Rocha Filho 2012) and additives to fodders for livestock (Chatzifotis et al. 2005) and fish (Gouveia et al. 2003). They are also commonly used in food industry as food pigments (Carocho et al. 2015). According to the data published in the report "The Global Market for Carotenoids" in 2014, the world's carotenoid market has achieved a value of $1.5 \mathrm{bn}$ USD, and it is forecast that in 2018, it will increase to 1.8 bn USD (BCC Research 2016). The increasing consumer awareness on the negative effect of synthetic pigments on human health and on the healthy diet trend causes increasing interest in natural pigments (Panesar 2014). The use of microorganisms as bioreactors for the production of carotenoids can constitute an alternative for chemical synthesis (Del Campo et al. 2007). Microbiological synthesis is a more effective method in comparison to extraction from vegetables or chemical synthesis. The most important advantages of the process include the possibility to decrease its costs by the use of improved strains and inexpensive (often waste) carbon and nitrogen sources in culture media (Buzzini 2000).

\section{Mechanism of carotenoid biosynthesis}

Rhodotorula glutinis are capable of synthesizing $\beta$-carotene, torulene, and torularhodin, the percentage of which depends on the cultivation conditions (Latha et al. 2005). The first stage of carotenoid biosynthesis includes the conversion of acetyl-CoA to 3-hydroxy-3-methylglutaryl-CoA with the participation of hydroxymethylglutaryl-CoA synthase. Subsequently, HMG-CoA is transformed to mevalonic acid (MVA) by specific reductase. As a result of subsequent changes, the compound is subjected to phosphorylation in a reaction catalyzed by specific kinases and decarboxylation to isopentenyl diphosphate (IPP). The IPP isomerization reaction leads to the formation of dimethylallyl pyrophosphate (DMAPP) and then to the DMAPP as a result of the addition reaction of three IPP molecules. These reactions lead to the formation of geranylgeranyl pyrophosphate (GGPP) containing 20 carbon atoms. Condensation of two GGPP molecules is catalyzed by phytoene synthase, leading to the formation of phytoene (first 40-carbon product of the pathway). This compound is then converted to neurosporene with the participation of phytoene desaturase. Neurosporene molecule may be transformed to lycopene or $\beta$-zeacarotene (Goodwin 1980; Hayman et al. 1974; Simpson et al. 1964). A second reaction probably takes place due to the presence of inhibitors, such as diphenylamine or in the case of environmental stress (Johnson and Lewis 1979). Then $\gamma$-carotene is formed as a result of lycopene cyclization. This compound can be produced in yeast cells also as a result of $\beta$-zeacarotene dehydrogenation reaction (Hayman et al. 1974). The $\gamma$-carotene cyclization reaction, catalyzed by $\beta$-lycopene cyclase, leads to the formation of a $\beta$-carotene molecule. Moreover, the $\gamma$-carotene molecule constitutes a precursor of torulene synthesis. Torularhodin is produced as a result of further transformations 
of torulene, consisting in hydroxylation and oxygenation reactions (Goodwin 1980) (Fig. 1).

\section{Influence of selected factors on the efficiency of biosynthesis and total carotenoids profile}

The efficiency of carotenoid biosynthesis by $R$. glutinis depends on numerous factors. The types of carbon and nitrogen sources have significant influence, and their preferred form and concentration may differ depending on the yeast strains (Buzzini and Martini 1999; El-Banna et al. 2012; Latha et al. 2005; Panesar et al. 2013). Due to this, selection of the correct carbon and nitrogen source constitutes one of the most important tasks for the determination of the culture medium composition.

One of the factors that stimulate the biosynthesis of carotenoid pigments is light. An increase in the content of these compounds under illumination conditions probably stems from the higher activity of enzymes involved in the biosynthetic pathway (Frengova and Beshkova 2009). An example here is the study of Zhang et al. (2014), in which R. glutinis cultures were subjected to illumination with LED lamps (800$2400 \mathrm{~mol} / \mathrm{m}^{2} \mathrm{~s}$ ). The carotenoid productivity was observed to be maximum $(2.6 \mathrm{mg} / \mathrm{L})$ when the culture was illuminated with three LED lamps, which constituted over 2-fold increase compared to the control culture $(1.2 \mathrm{mg} / \mathrm{L})$. In this case, inhibitory influence of illumination on the yeast's growth was not observed. Cellular biomass yields after $60 \mathrm{~h}$ for the control culture and the culture illuminated with two and three LED lamps amounted to $15.9,17.4$, and $17.7 \mathrm{~g} / \mathrm{L}$, respectively. Bhosale and Gadre (2002) carried out $R$. glutinis NCIM 3353 no. 32 yeast cultures at a constant illumination with an intensity of $1000 \mathrm{~lx}$. This amount of illumination used considerably slowed down the growth of the studied yeast strain. The carotenoid concentration decreased from 125 to $83 \mathrm{mg} / \mathrm{L}$, after $72 \mathrm{~h}$ of cultivation in $30^{\circ} \mathrm{C}$. Cultures were also conducted beginning illumination at the late logarithmic growth phase. This measure increased the carotenoid productivity to $198 \mathrm{mg} /$ L. Sakaki et al. (2001) conducted a study on the influence of white light $(3500 \mathrm{~lx})$ on the carotenoid biosynthesis using a wild strain of $R$. glutinis no. 21. It was determined that the culture illumination intensified the production of all carotenoid fractions, in particular torularhodin. The $\beta$-carotene, torulene, and torularhodin production increased from 3.6, 29.2 , and 7.9 to $4.2,32.2$, and $14.2 \mathrm{mg} / 100 \mathrm{~g}_{\text {d.w. }}$, respectively.

Temperature is an important parameter that regulates the biosynthesis of carotenoids, and the activity of the enzymes that participate in their production process depends upon it (Frengova et al. 1995). $\beta$-Carotene synthesis by R. glutinis is increased at lower temperature. This situation is reversed in the case of torulene and torularhodin; their production is increased at higher temperatures (Nakayama et al. 1954).
Perhaps, at lower temperature, the enzymes engaged in the torulene biosynthesis are less active (Bhosale 2004). The study of Simpson et al. (1964) demonstrated that after 21 days of culture at a temperature of $5{ }^{\circ} \mathrm{C}$, the $\beta$-carotene content in the biomass of $R$. glutinis amounted to $64 \%$ and torulene and torularhodin to 4.4 and $4.8 \%$, respectively. After 12 days of culture of the same strain at $25{ }^{\circ} \mathrm{C}$, these values amounted to $25.2,27.8$, and $24.3 \%$, respectively. Similar results were obtained by Frengova et al. (1995). When a coculture of the yeast R. glutinis $22 \mathrm{P}$ and the bacteria Lactobacillus helveticus 124 was cultivated at $20^{\circ} \mathrm{C}, \beta$-carotene, torulene, and torularhodin content amounted to $19.0,22.8$, and $56.0 \%$, respectively. At $35{ }^{\circ} \mathrm{C}$, considerable increase in the production of torularhodin was observed $(78.3 \%)$, whereas that of $\beta$-carotene and torulene was low and amounted to 9.6 and $9.0 \%$. Moreover, an elevation of the culture temperature from 20 to $35^{\circ} \mathrm{C}$ led to a significant increase in the productivity of carotenoid biosynthesis - its content increased from 145.4 to $280.0 \mu \mathrm{g} / \mathrm{g}_{\text {d.w. }}$.

$R$. glutinis is an aerobic microorganism, and thus ensuring correct aeration is the necessary condition for carotenoid biosynthesis (Saenge et al. 2011b). Frengova and Beshkova (2009) have stated that in the case of yeasts of the genus Rhodotorula, the rate at which the culture is mixed should be in the range from 180 to $190 \mathrm{rpm}$, and the air flow should range from 0.5 to $1.9 \mathrm{~L} / \mathrm{min}$. Aksu and Eren (2007) have reported that increase in the aeration rate from 0 to $2.4 \mathrm{vvm}$ significantly increased carotenoid biosynthesis by $R$. glutinis. The total biosynthetic efficiency increased from 63.4 to $105.8 \mathrm{mg} / \mathrm{L}$ after 10 days of cultivation.

Supplementing the culture medium with certain metal ions can increase carotenoid biosynthesis by $R$. glutinis (Bhosale and Gadre 2001b; El-Banna et al. 2012). El-Banna et al. (2012) studied the influence of magnesium, zinc, iron (II), copper, manganese, and calcium salts on the efficiency of the process. The highest content of these compounds $\left(638 \mu \mathrm{g} / \mathrm{g}_{\text {d.w. }}\right)$ in the biomass was reported when the culture medium was supplemented with $0.1 \%$ of zinc sulfate (VI). In comparison to the control medium $\left(292 \mu \mathrm{g} / \mathrm{g}_{\text {d.w. }}\right)$, almost 2 fold increase in carotenoid content was reported in the yeast biomass. Also, enriching the culture medium with iron (II) sulfate (VI) and copper sulfate (VI) increased its content to 460 and $674 \mu \mathrm{g} / \mathrm{g}_{\text {d.w. }}$, respectively.

The presence of different solvents and chemical compounds in the culture medium can also intensify the carotenoid production by $R$. glutinis. Saenge et al. (2011b) studied the influence of the addition of three surfactants, such as Tween 20, Tween 80, and gum arabic, on the carotenoid biosynthesis by the yeast $R$. glutinis TISTR 5159 . It was determined that the presence of Tween 20 in the culture medium had the most efficient influence in increasing carotenoid productivity $(108.94 \mathrm{mg} / \mathrm{L})$ compared to the control culture $(65.86 \mathrm{mg} / \mathrm{L})$. The presence of chemical compounds has also impact on proportion of the synthesized carotenoids. It was 
reported that the addition of ethanol to the culture medium stimulates production of $\beta$-carotene and torulene but inhibits the synthesis of torularhodin (Bhosale 2004). Kim et al. (2004) reported that the addition of phenol at a concentration of $500 \mathrm{ppm}$ to the medium increased the production of $\beta$ carotene by $35 \%$. This measure limited the torularhodin synthesis, whereas the torulene content remained at a stable level.

The efficiency of biosynthesis and composition of the fractions of carotenoids synthesized by the $R$. glutinis yeast mainly depends on the strain and the culture conditions. Nowadays, great potential in this area provides also the techniques of genetic modification. Bhosale and Gadre (2001a) used UV radiation (250-280 nm) to modify wild strain of $R$. glutinis NCIM 3353. Selected for further study, yellow-colored mutant no. 32 produced 120 -fold more $\beta$-carotene than the parent strain. $\beta$-Carotene was $82 \%(w / w)$ of the total carotenoid

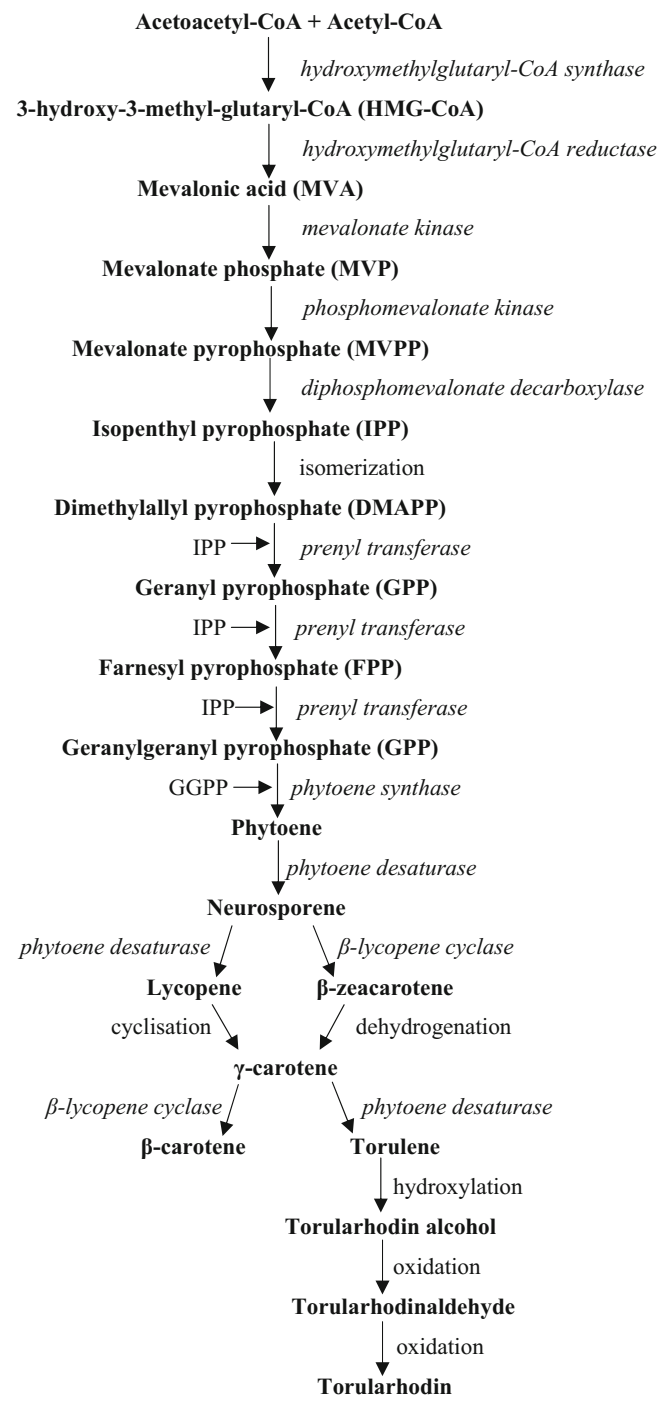

Fig. 1 Carotenoid biosynthetic pathway in Rhodotorula species (elaborated on the basis of Frengova and Beshkova 2009; Goodwin 1980; Hayman et al. 1974; Johnson and Lewis 1979; Simpson et al. 1964; Squina and Mercadante 2005) content, whereas parent strain produced only $14 \%$ of this compound. Sakaki et al. (2000) conducted a mutagenizing of $R$. glutinis strain no. 21 isolated from soil by UV radiation $(254 \mathrm{~nm})$. As a result of this procedure, authors obtained the mutant TL/21. This yeast synthesized 3 -fold more torularhodin $\left(4.3 \mathrm{mg} / 100 \mathrm{~g}_{\text {d.w. }}\right)$ than the parent strain $\left(1.5 \mathrm{mg} / 100 \mathrm{~g}_{\text {d.w. }}\right)$.

\section{Industrial use of carotenoids produced by $R$. glutinis}

$\beta$-Carotene is the most desired carotenoid type, commonly used as pigment in foods and diet supplements (Carocho et al. 2015; Schierle et al. 2004). Currently, torulene and torularhodin are not commercially used. It is generally known that torulene $\left(\mathrm{C}_{40} \mathrm{H}_{54}\right)$ exhibits properties of provitamin $\mathrm{A}$ and antioxidative effect (Maldonade et al. 2008). It was determined in an in vitro study that torularhodin $\left(\mathrm{C}_{40} \mathrm{H}_{52} \mathrm{O}_{2}\right)$, carboxylated torulene derivative, has greater capacity to neutralize free radicals compared to $\beta$-carotene (Sakaki et al. 2001). Scarce scientific publications have indicated the possibility to use torulene and torularhodin as components of cosmetics and food (Zoz et al. 2015), and as ingredients of drugs (Ungureanu and Ferdes 2012). Toxicity studies conducted on rats demonstrated that $\beta$-carotene, torulene, and torularhodin produced by $R$. glutinis DFR-PDY yeasts can be used as safe food additives (Latha and Jeevaratanm 2012). The capacity of $R$. glutinis to synthesize carotenoids can be also used for medical purposes, for example, dried and powdered $R$. glutinis NCIM 3353 yeasts biomass added to the fodder for rats. It was determined that it exhibited protective effects against the precancerous lesions of the liver induced by $\mathrm{N}$-nitrosodimethylamine (Bhosale et al. 2002). Moreover, torulene and torularhodin inhibit the growth of prostate cancer ( $\mathrm{Du}$ et al. 2016). Torularhodin can be also used as a neuroprotective agent against $\mathrm{H}_{2} \mathrm{O}_{2}$-induced oxidative stress, due to its strong antioxidant activity (Wu et al. 2015).

\section{Biosynthesis of phenylalanine ammonia lyase by $\boldsymbol{R}$. glutinis}

$R$. glutinis, depending on the culture conditions, has the capacity to synthesize different types of enzymes that can be used in various industrial sectors. It was determined that the biomass of these yeasts can be source of lipases (Hatzinikolaou et al. 1999; Khayati and Alizadeh 2013; Papaparaskevas et al. 1992), $\alpha$-L-arabinofuranosidase (EC 3.2.1.55) (Martínez et al. 2006), invertase (EC 3.2.1.26) (Canli et al. 2011; Rubio et al. 2002), pectinases, and tannin acyl hydrolase (EC 3.1.1.20) (Taskin 2013). However, researches have focused primarily on the possibility to obtain phenylalanine ammonia lyase (E.C.4.3.1.5). As a result of the 
effect of this enzyme, it is possible to obtain L-phenylalanine, which constitutes the substrate for aspartame production (D’Cunha et al. 1996a, 1996b; Zhu et al. 2014).

Phenylalanine ammonia lyase (PAL) catalyzes the nonoxidative process of phenylalanine transformation to trans-cinnamic acid and ammonia (D'Cunha et al. 1996a, 1996b). Under controlled conditions, this reaction may also take place in a reverse direction (Takac et al. 1995). In the food industry, this enzyme is used in the production of L-phenylalanine and para-hydroxycinnamic acid (Cui et al. 2015), and in medicine in phenylketonuria therapy (Longo et al. 2014; Sarkissian and Gámez 2005) and neoplastic cancers in mice (D'Cunha 2005). Furthermore, the activity of PAL is used to determine the concentration of L-phenylalanine in blood plasma (Watanabe et al. 1992).

The enzyme phenylalanine ammonia lyase occurs in common in microorganism cells. It was isolated from the cells of Streptomyces verticillatus (Bezanson et al. 1970), Rhizoctonia solani (Kalghatgi and Subba Rao 1975), and Neurospora crassa (Sikora and Marzluf 1982). However, the largest producers of PAL are yeasts of the genus Rhodotorula. In the yeast cells, this enzyme participates in the absorption of phenylalanine as the source of carbon and nitrogen (Gientka et al. 2006).

Numerous research teams (D'Cunha et al. 1996b; Takac et al. 1995; Yamada et al. 1981) conducted studies on the obtainment of L-phenylalanine in the presence of PAL originating from the cells of $R$. glutinis. To grow yeast cells, media containing easily assimilated nutrient sources are used. Glucose is used as the source of carbon and yeast extract as that of nitrogen. Culture media are also supplemented with zinc, magnesium, iron, cobalt, and calcium salts. The grown yeast cells are then transferred to a medium, in which phenylalanine ammonia lyase induction occurs. The following compounds act as inducers: L-phenylalanine, D,L-phenylalanine, L-tyrosine, D,L-tyrosine, and L-isoleucin. Typical L-phenylalanine dose, which induces PAL production, is $0.4-0.5 \%$; higher concentrations do not have a significant effect on activity of the enzyme. Yeast cultures on inductive medium is conducted to the moment, when the phenylalanine ammonia lyase activity achieves the level of at least $0.2-2.0 \mathrm{U} / \mathrm{ml}$ (Gientka et al. 2006).

Bioconversion of trans-cinnamic acid to L-phenylalanine is carried out with isolated enzyme or directly with yeast cells rich in PAL (Gientka et al. 2006). One of the factors that determine the course of the process is the acidity of the environment. Yamada et al. (1981) and Evans et al. (1987) have stated that the optimal $\mathrm{pH}$ for the bioconversion process of cells of $R$. glutinis is 10.0, whereas El-Batal et al. (2000) concluded that for $R$. glutinis mutants, this value is equal to 11.0. The $\mathrm{pH}$ value of the reaction environment should not be less than 9.0 because the deamination of Lphenylalanine to trans-cinnamic acid takes place under this value (Gientka et al. 2006).
In order to obtain the maximum efficiency of the bioconversion process, it is important to determine the optimal concentration of trans-cinnamic acid in the reaction environment. The reaction occurred under the conditions of its excess; however, it was determined that very high concentration of transcinnamic acid inhibits the activity of phenylalanine ammonia lyase. The terminal concentration of the acid in the reaction environment should not exceed $50 \mathrm{mM}$ (Takac et al. 1995).

The factor determining to a large extent the activity of phenylalanine ammonia lyase is the temperature. Takac et al. (1995) determined that the bioconversion process of transcinnamic acid to L-phenylalanine takes place most efficiently at a temperature of $30^{\circ} \mathrm{C}$. On the other hand, increasing the temperature to $40^{\circ} \mathrm{C}$ decreased the concentration of the amino acid by approximately $50 \%$. The bioconversion process is further influenced by the presence of different types of chemical compounds in the reaction medium. The same research team noticed that the addition of sodium glutamate and penicillin increased the activity and stability of phenylalanine ammonia lyase during the bioconversion process. On the other hand, the presence of $\mathrm{Cl}^{-}$ions in the culture environment has inhibitory effect on the process.

The elaboration of an efficient method that warrants the maintenance of PAL stability and activity, so that the enzyme could be used in a constant process, constitutes an important issue. D'Cunha et al. (1996b) observed that immobilization of R. glutinis NCYC 61 cells did not prevent the degradation of phenylalanine ammonia lyase, which made it impossible to use the yeast cells again. However, it was noticed that the addition of $\mathrm{Mg}^{2+}$ ions and glycerol to the reaction environment stabilized PAL. The addition of $4 \mathrm{mM}$ of $\mathrm{MgSO}_{4}$ and $10 \%$ glycerol enabled to obtain L-phenylalanine in nine production cycles, whereas the immobilized enzyme lost its activity in the fourth production cycle. D'Cunha (2005) devoted the next study to obtain increased level of phenylalanine ammonia lyase from the culture of $R$. glutinis. The process consisting in the use of entire yeast cells had low efficiency due to the low permeability of the cellular membrane for Lphenylalanine, the effect of ultrasonication, detergents, and enzymes on the increase of PAL activity were tested. Ultrasonication turned out to be the most efficient method, with which the enzyme activity could be increased 10 times compared to the control.

\section{Conclusions and future prospects}

Recently, the use of products synthesized microbiologically has been increased in various industrial sectors. Due to its capacity to produce metabolites, Rhodotorula glutinis may become an important link of development in modern biotechnology. This yeast belongs to the group of oleaginous microorganisms and is capable to producing and accumulating even 
$60 \%$ of lipids in dry cellular substance (Dai et al. 2007). Due to the participation of individual fatty acids, these lipids can be used as substrates for third-generation biodiesel production. Dynamically increasing production of unconventional fuels such as biodiesel is the result of decrease of nonrenewable sources such as petroleum and environmental care. The use of $R$. glutinis yeast as bioreactors for the production of microbial oils is currently limited by expensive production. It may be assumed that further study will focus on increasing the biosynthetic efficiency by optimization cultivation conditions and by genetically modifying the organisms. Moreover, another direction of research should concentrate on the use of extracted biomass, which after removal of solvents could be added to animal feed. This use of waste yeast biomass, which contains mainly proteins and polysaccharides, additionally increases profitability of the microbial production of SCO.

In recent years, there has been an increased consumer knowledge of negative impact of synthetic colorants on health. Therefore, researchers are looking for new producers of natural dyes (Torres et al. 2016). R. glutinis are capable of synthesizing $\beta$-carotene, and two other carotenoidstorularhodin and torulene. These compounds have not been detected in foods, and probably of this, their effects on the human health have not been investigated and described yet. However, taking into account their chemical structure and properties, it seems clear that these two substances can be used as food additives (Zoz et al. 2015). Furthermore, torulene and torularhodin have the potential to be used in medicine and pharmacy. The first direction of their use may be the prevention of prostate cancer (Du et al. 2016). Torularhodin has strong antimicrobial properties, and it may become a new natural antibiotic (Keceli et al. 2013; Ungureanu and Ferdes 2012). Antimicrobial properties of torularhodin can be also used in the production of films for coating of medical implants (Ungureanu et al. 2014, 2016). These examples describe the prospects for the use of carotenoids synthesized by the $R$. glutinis; however, it is necessary to perform additional nutritional and toxicological tests that will allow for the introduction of torulene and torularhodin on the commercial market.

$R$. glutinis yeast can be source of various types of enzymes that can be used in various industrial sectors, especially phenylalanine ammonia lyase. This enzyme is accumulated intracellularly, and thus, the most promising appears to be the use of whole cells in the biotransformation of trans-cinnamic acid to L-phenylalanine. This would reduce the costs associated with the disintegration and enzyme secretion, after biotransformation of yeast biomass can be used as an animal feed additive.

This bibliographical review has shown that $R$. glutinis yeasts have great potential for industrial applications. Cultivation of these yeasts is independent of the climate and season, and the production cycle is short. In addition, the $R$. glutinis yeasts are capable to metabolize different substances as sources of carbon and nitrogen, so the use of many waste materials as components of culture media is possible. As a result, the biodegradable industrial waste with simultaneous production of yeast biomass containing valuable nutrients is possible (Kieliszek et al. 2015). However, still it is necessary to conduct studies on reducing the cost of obtaining lipids, carotenoids, and enzymes from $R$. glutinis yeast biomass for the industrialization these processes.

\section{Compliance with ethical standards}

Conflict of interest The authors declare no conflict of interest.

Compliance with ethics requirements This article does not contain any studies with human or animal subjects.

Open Access This article is distributed under the terms of the Creative Commons Attribution 4.0 International License (http:// creativecommons.org/licenses/by/4.0/), which permits unrestricted use, distribution, and reproduction in any medium, provided you give appropriate credit to the original author(s) and the source, provide a link to the Creative Commons license, and indicate if changes were made.

\section{References}

Adamczak M, Bornscheuer UT, Bednarski W (2009) The application of biotechnological methods for the synthesis of biodiesel. Eur J Lipid Sci Technol 111:808-813. doi:10.1002/ejlt.200900078

Aksu Z, Eren AT (2007) Production of carotenoids by the isolated yeast of Rhodotorula glutinis. Biochem Eng J 35:107-113. doi:10.1016/j. bej.2007.01.004

Almazan O, Klibansky M, Otero MA (1981) Microbial fat synthesis by Rhodotorula glutinis from blackstrap molasses in continuous culture. Biotechnol Lett 3:663-666. doi:10.1007/BF00158697

Alvarez RM, Rodriguez B, Romano JM, Diaz AO, Gómez E, Miró D, Navarro L, Saura G, Garcia JL (1992) Lipid accumulation in Rhodotorula glutinis on sugar cane molasses in single-stage continuous culture. World J Microbiol Biotechnol 8:214-215. doi:10. 1007/BF01195853

Anunciato TP, da Rocha Filho PA (2012) Carotenoids and polyphenols in nutricosmetics, nutraceuticals, and cosmeceuticals. J Cosmet Dermatol 11:51-54. doi:10.1111/j.1473-2165.2011.00600.x

Barnett JA (2004) A history of research on yeasts 8: taxonomy. Yeast 21: 1141-1193. doi:10.1002/yea.1154

BCC Research: The Global Market for Carotenoids, http://www. bccresearch.com/market-research/food-and-beverage/carotenoidsglobal-market-report-fod025e.html, Accessed 29 Jan 2016

Beopoulos A, Nicaud JM (2012) Yeast: a new oil producer? OCL 19:2228. doi:10.1051/ocl.2012.0426

Beopoulos A, Cescut J, Haddouche R, Uribelarrea JL, Molina-Jouve C, Nicaud JM (2009) Yarrowia lipolytica as a model for bio-oil production. Prog Lipid Res 48:375-387. doi:10.1016/j.plipres.2009.08. 005

Bezanson GS, Desaty D, Emes AV, Vining LC (1970) Biosynthesis of cinnamamide and detection of phenylalanine ammonia-lyase in Streptomyces verticillatus. Can J Microbiol 16:147-151. doi:10. $1139 / \mathrm{m} 70-026$

Bhosale P (2004) Environmental and cultural stimulants in the production of carotenoids from microorganisms. Appl Microbiol Biotechnol 63:351-361. doi:10.1007/s00253-003-1441-1 
Bhosale P, Gadre RV (2001a) $\beta$-carotene production in sugarcane molasses by a Rhodotorula glutinis mutant. J Ind Microbiol Biot 26:327332. doi:10.1038/sj.jim. 7000138

Bhosale P, Gadre RV (2001b) Production of $\beta$-carotene by a mutant of Rhodotorula glutinis. Appl Microbiol Biotechnol 55:423-427. doi: $10.1007 / \mathrm{s} 002530000570$

Bhosale P, Gadre RV (2002) Manipulation of temperature and illumination conditions for enhanced $\beta$-carotene production by mutant 32 of Rhodotorula glutinis. Lett Appl Microbiol 34:349-353. doi:10. 1046/j.1472-765X.2002.01095.X

Bhosale P, Motiwale L, Ingle AD, Gadre RV, Rao KVK (2002) Protective effect of Rhodotorula glutinis NCIM 3353 on the development of hepatic preneoplastic lesions. Curr Sci 83:303-308

Biswas SK, Yokoyama K, Nishimura K, Miyaji M (2001) Molecular phylogenetics of the genus Rhodotorula and related basidiomycetous yeasts inferred from the mitochondrial cytochrome $b$ gene. Int $\mathrm{J}$ Syst Evol Microbiol 51:1191-1199. doi:10.1099/00207713-51-31191

Braunwald T, Schwemmlein L, Graeff-Hönninger S, French WT, Hernandez R, Holmes WE, Claupein W (2013) Effect of different $\mathrm{C} / \mathrm{N}$ ratios on carotenoid and lipid production by Rhodotorula glutinis. Appl Microbiol Biotechnol 97:6581-6588. doi:10.1007/ s00253-013-5005-8

Buzzini P (2000) An optimization study of carotenoid production by Rhodotorula glutinis DBVPG 3853 from substrates containing concentrated rectified grape must as the sole carbohydrate source. J Ind Microbiol Biotechnol 24:41-45. doi:10.1038/sj.jim.2900765

Buzzini P, Martini A (1999) Production of carotenoids by strains of Rhodotorula glutinis cultured in raw materials of agro-industrial origin. Bioresour Technol 71:41-44. doi:10.1016/S0960-8524(99) 00056-5

Canli O, Erdal S, Taskin M, Kurbanoglu EB (2011) Effects of extremely low magnetic field on the production of invertase by Rhodotorula glutinis. Toxicol Ind Health 27:35-399. doi:10.1177/ 0748233710380219

Carocho M, Morales P, Ferreira ICFR (2015) Natural food additives: Quo vadis? Trends Food Sci Technol 45:284-295. doi:10.1016/j.tifs. 2015.06.007

Chatzifotis S, Pavlidis M, Jimeno CD, Vardanis G, Sterioti A, Divanach P (2005) The effect of different carotenoid sources on skin coloration of cultured red porgy (Pagrus pagrus). Aquac Nutr 36:1517-1525. doi:10.1111/j.1365-2109.2005.01374.x

Cheirsilp B, Suwannarat W, Niyomdecha R (2011) Mixed culture of oleaginous yeast Rhodotorula glutinis and microalga Chlorella vulgaris for lipid production from industrial wastes and its use as biodiesel feedstock. New Biotechnol 28:362-368. doi:10.1016/j. nbt.2011.01.004

Cheirsilp B, Kitcha S, Torpee S (2012) Co-culture of an oleaginous yeast Rhodotorula glutinis and a microalga Chlorella vulgaris for biomass and lipid production using pure and crude glycerol as a sole carbon source. Ann Microbiol 62:987-993. doi:10.1007/s13213-011-0338$\mathrm{y}$

Cui J, Liang L, Han C, Liu RL (2015) Stabilization of phenylalanine ammonia lyase from Rhodotorula glutinis by encapsulation in polyethyleneimine-mediated biomimetic silica. Appl Biochem Biotechnol 176:999-1011. doi:10.1007/s12010-015-1624-0

Cutzu R, Coi A, Rosso F, Bardi L, Ciani M, Budroni M, Zara G, Zara S, Mannazzu I (2013) From crude glycerol to carotenoids by using a Rhodotorula glutinis mutant. World J Microbiol Biotechnol 29: 1009-1017. doi:10.1007/s11274-013-1264-x

Dai C, Tao J, Xie F, Dai Y, Zhao M (2007) Biodiesel generation from oleaginous yeast Rhodotorula glutinis with xylose assimilating capacity. Afr J Biotechnol 6:2130-2134

D'Cunha GB (2005) Enrichment of phenylalanine ammonia lyase activity of Rhodotorula yeast. Enzym Microb Technol 36:498-502. doi: 10.1016/j.enzmictec.2004.11.006
D'Cunha GB, Satyanarayan V, Nair PM (1996a) Purification of phenylalanine ammonia lyase from Rhodotorula glutinis. Phytochemistry 42:17-20. doi:10.1016/0031-9422(95)00914-0

D'Cunha GB, Satyanarayan V, Nair PM (1996b) Stabilization of phenylalanine ammonia lyase containing Rhodotorula glutinis cells for the continuous synthesis of L-phenylalanine methyl ester/96/. Enzym Microb Technol 19:421-427. doi:10.1016/S0141-0229(96)00013-0

Del Campo JA, García-González M, Guerrero MG (2007) Outdoor cultivation of microalgae for carotenoid production: current state and perspectives. Appl Microbiol Biotechnol 74:1163-1174. doi:10. 1007/s00253-007-0844-9

Du C, Li Y, Guo Y, Han M, Zhang W, Qian H (2016) The suppression of torulene and torularhodin treatment on the growth of PC-3 xenograft prostate tumors. Biochem Biophys Res Commun 469:1146-1152. doi:10.1016/j.bbrc.2015.12.112

Easterling ER, French WT, Hernandez R, Licha M (2009) The effect of glycerol as a sole and secondary substrate on the growth and fatty acid composition of Rhodotorula glutinis. Bioresour Technol 100: 356-361. doi:10.1016/j.biortech.2008.05.030

El-Banna AA, El-Razek AMA, El-Mahdy AR (2012) Some factors affecting the production of carotenoids by Rhodotorula glutinis var. glutinis. Food Nutr Sci 3:64-71. doi:10.4236/fns.2012.31011

El-Batal AI, Abo-State M, Shibab A (2000) Phenylalanine ammonia lyase production by gamma irradiated and analog-resistant mutants of Rhodotorula glutinis. Acta Microbiol Pol 49:51-61

Evans CT, Hanna K, Payne C, Conrad D, Misawa M (1987) Biotransformation of trans-cinnamic acid to 1-phenylalanine: optimization of reaction conditions using whole yeast cells. Enzym Microb Technol 9:417-421. doi:10.1016/0141-0229(87)90137-2

Fell JW, Statzell-Tallman A (1998) "Rhodotorula" Harison. In: Kurtzman A, Fell A (eds) The yeast, a taxonomic study, 4th edn. Elsevier, Amsterdam, pp 800-827

Fickers P, Benetti PH, Wachè Y, Marty A, Mauersberger S, Smit MS, Nicaud JM (2005) Hydrophobic substrate utilisation by the yeast Yarrowia lipolytica, and its potential applications. FEMS Yeast Res 5:527-543. doi:10.1016/j.femsyr.2004.09.004

Fraser PD, Bramley PM (2004) The biosynthesis and nutritional uses of carotenoids. Prog Lipid Res 43:228-265. doi:10.1016/j.plipres. 2003.10.002

Frengova GI, Beshkova DM (2009) Carotenoids from Rhodotorula and Phaffia: yeasts of biotechnological importance. J Ind Microbiol Biotechnol 36:163-180. doi:10.1007/s10295-008-0492-9

Frengova GI, Simova ED, Beshkova DM (1995) Effect of temperature changes on the production of yeast pigments co-cultivated with lacto-acid bacteria in whey ultrafiltrate. Biotechnol Lett 17:10011006. doi:10.1007/BF00127443

Gientka I, Błażejak S, Duszkiewicz-Reinhard W (2006) Bioconversion of trans-cinnamic acid to L-phenylalanine by Rhodotorula sp. Biotechnologia 2:117-129

Gonzalez-Garcia Y, Hernandez R, Zhang G, Escalante FME, Holmes W, French WT (2013) Lipids accumulation in Rhodotorula glutinis and Cryptococcus curvatus growing on distillery wastewater as culture medium. Environ Prog Sustain Energy 32:69-74. doi:10.1002/ep. 10604

Goodwin TW (1980) Biosynthesis of carotenoids. In: Goodwin TW (ed) The biochemistry of the carotenoids, vol 1. Chapman and Hall, London, pp 33-76. doi:10.1007/978-94-009-5860-9 2

Gouveia I, Rema P, Pereira O, Empis J (2003) Colouring ornamental fish (Cyprinus carpio and Carassius auratus) with microalgal biomass. Aquac Nutr 9:123-129. doi:10.1046/j.1365-2095.2003.00233.x

Ham KS, Rhee JS (1998) Property characterization and lipid compositional analysis of lipid granules isolated from an oleaginous yeast Rhodotorula glutinis. J Food Sci Nutr 3:211-215

Hatzinikolaou DG, Kourentzi E, Stamatis H, Christakopoulos P, Kolisis FN, Kekos D, Macris BJ (1999) A novel lipolytic activity of Rhodotorula glutinis cells: production, partial characterization and 
application in the synthesis of esters. J Biosci Bioeng 88:53-56. doi: 10.1016/S1389-1723(99)80175-3

Hayman EP, Yokoyama H, Chichester CO, Simpson KL (1974) Carotenoid biosynthesis in Rhodotorula glutinis. J Bacteriol 120: 1339-1343

Hernández-Almanza A, Montanez JC, Aguilar-González MA, MartínezÁvila C, Rodríguez-Herrera R, Aguilar CN (2014) Rhodotorula glutinis as source of pigments and metabolites for food industry. Food Biosci 5:64-72. doi:10.1016/j.fbio.2013.11.007

Hirosawa N, Takada H (1969) Salt susceptibility of Rhodotorula glutinis var. salinaria isolated from salt farm in Japan. Trans Mycol Soc Jpn 10:35-39

ITIS Standard Report Page: Rhodotorula glutinis, http://www.itis.gov/ servlet/SingleRpt/SingleRpt? search_topic $=$ TSN\&search_value= 194694, Accessed 17 Jan 2016

Johnson EA, Lewis M (1979) Astaxanthin formation by the yeast Phaffia rhodozyma. J Gen Microbiol 115:173-183. doi:10.1099/00221287115-1-173

Johnson V, Singh M, Saini VS, Sista VR, Yadav NK (1992) Effect of pH on lipid accumulation by an oleaginous yeast: Rhodotorula glutinis IIP-30. World J Microbiol Biotechnol 8:382-384. doi:10.1007/ BF01198749

Johnson VW, Singh M, Saini VS, Adhikari DK, Sista V, Yadav NK (1995) Utilization of molasses for the production of fat by an oleaginous yeast Rhodotorula glutinis IIP-30. J Ind Microbiol 14:1-4. doi:10.1007/BF01570057

Kalghatgi KK, Subba Rao PV (1975) Microbial L-phenylalanine ammonia-lyase. Purification, subunit structure and kinetic properties of the enzyme from Rhizoctonia solani. Biochem J 149:65-72

Keceli TM, Erginkaya Z, Turkkan E, Kaya U (2013) Antioxidant and antibacterial effects of carotenoids extracted from Rhodotorula glutinis strains. Asian J Chem 25:42-46. doi:10.14233/ajchem. 2013.12377

Khayati G, Alizadeh S (2013) Extraction of lipase from Rhodotorula glutinis fermentation culture by aqueous two-phase partitioning. Fluid Phase Equilib 353:132-134. doi:10.1016/j.fluid.2013.05.037

Kieliszek M, Błażejak S, Gientka I, Bzducha-Wróbel A (2015) Accumulation and metabolism of selenium by yeast cell. Appl Microbiol Biotechnol 99:5373-5382. doi:10.1007/s00253-0156650-x

Kim BK, Park PK, Chae HJ, Kim EY (2004) Effect of phenol on $\beta$ carotene content in total carotenoids production in cultivation of Rhodotorula glutinis. Korean J Chem Eng 21:689-692. doi:10. 1007/BF02705506

Kot AM, Błażejak S, Kurcz A, Gientka I (2015) Drożdże jako potencjalne źródło tłuszczu mikrobiologicznego. Post Mikrobiol 54:364-373

Krinsky NI, Johnson EJ (2005) Carotenoid actions and their relation to health and disease. Mol Asp Med 26:459-516. doi:10.1016/j.mam. 2005.10.001

Krzyściak P, Halska A, Macura AB (2007) Występowanie i chorobotwórczość grzybów Rhodotorula spp. Post Mikrobiol 46: 291-300

Latha BV, Jeevaratanm K (2012) Thirteen-week oral toxicity study of carotenoid pigment from Rhodotorula glutinis DFR-PDY in rats. Indian J Exp Biol 50:645-651

Latha BV, Jeevaratnam K, Murali HS, Manja KS (2005) Influence of growth factors on carotenoid pigmentation of Rhodotorula glutinis DFR-PDY from natural source. Indian J Biotechnol 4:353-357

Lee K, Yoon SH (1990) Effects of cultural conditions on the production and characteristic of unsaponifable lipids in Rhodotorula glutinis. Korean J Appl Microbiol Biotechnol 18:171-174

Li Q, Du W, Liu D (2008) Perspectives of microbial oils for biodiesel production. Appl Microbiol Biotechnol 80:749-756. doi:10.1007/ s00253-008-1625-9
Li Z, Sun H, Mo X, Li X, Xu B, Tian P (2013) Overexpression of malic enzyme (ME) of Mucor circinelloides improved lipid accumulation in engineered Rhodotorula glutinis. Appl Microbiol Biotechnol 97: 4927-4936. doi:10.1007/s00253-012-4571-5

Lian J, Chen S, Garcia-Perez M, Chen S (2013) Fermentation of levoglucosan with oleaginous yeasts for lipid production. Bioresour Technol 133:183-189. doi:10.1016/j.biortech.2010.07. 071

Liu Y, Wang Y, Liu H, Zhang J (2015) Enhanced lipid production with undetoxified corncob hydrolysate by Rhodotorula glutinis using a high cell density culture strategy. Bioresour Technol 180:32-39. doi: 10.1016/j.biortech.2014.12.093

Longo N, Harding CO, Burton BK, Grange DK, Vockey J, Wasserstein M, Rice GM, Dorenbaun A, Neuenburg JK, Musson DM, Gu H, Sile S (2014) Single-dose, subcutaneous recombinant phenylalanine ammonia lyase conjugated with polyethylene glycol in adult patients with phenylketonuria: an open-label, multicentre, phase 1 doseescalation trial. Lancet 384:37-44. doi:10.1016/S0140-6736(13) 61841-3

Lopes da Silva T, Feijão F, Roseiro JC, Reis A (2011) Monitoring Rhodotorula glutinis CCMI 145 physiological response and oil production growing on xylose and glucose using multi-parameter flow cytometry. Bioresour Technol 102:2998-3006. doi:10.1016/j. biortech.2010.10.008

Louhasakul Y, Cheirsilp B (2013) Industrial waste utilization for low-cost production of raw material oil through microbial fermentation. Appl Biochem Biotechnol 169:110-122. doi: 10.1007/s12010-012-9965-4

Maldonade IR, Rodriguez-Amaya DB, Scamparini ARP (2008) Carotenoids of yeasts isolated from the Brazilian ecosystem. Food Chem 107:145-150. doi:10.1016/j.foodchem.2007.07.075

Maoka T (2011) Carotenoids in marine animals. Mar Drugs 9:278-293. doi:10.3390/md9020278

Marova I, Carneck M, Halienov A, Breierova E, Koci AR (2010) Production of carotenoid-/ergosterol-supplemented biomass by red yeast Rhodotorula glutinis grown under external stress. Food Technol Biotechnol 48:56-61

Martínez C, Gertosio C, Labbe A, Pérez R, Ganga MA (2006) Production of Rhodotorula glutinis: a yeast that secretes $\alpha$-Larabinofuranosidase. Electron J Biotechnol 9:407-413. doi:10. 2225/vol9-issue4-fulltext-8

Mast B, Zöhrens N, Schmidl F, Hernandez R, French WT, Merkt N, Claupein W, Graeff-Hönninger S (2014) Lipid production for microbial biodiesel by the oleagenious yeast Rhodotorula glutinis using hydrolysates of wheat straw and miscanthus as carbon sources. Waste Biomass Valoriz 5:955-962. doi:10.1007/s12649014-9312-9

Nakayama T, MacKinney G, Phaff HJ (1954) Carotenoids in ascosporogenous yeasts. Antonie Van Leeuwenhoek 20:217-228

Panesar R (2014) Bioutilization of kinnow waste for the production of biopigments using submerged fermentation. Int J Food Sci Nutr 3: 9-13

Panesar R, Patil SD, Panesar PS (2013) Standardization of medium components and process parameters for biopigment production using Rhodotorula glutinis. Int J Food Ferment Technol 3:149-156. doi: 10.5958/2277-9396.2014.00343.2

Papanikolaou S, Aggelis G (2011a) Lipids of oleaginous yeasts. Part I: biochemistry of single cell oil production. Eur J Lipid Sci Technol 113:1031-1051. doi:10.1002/ejlt.201100014

Papanikolaou S, Aggelis G (2011b) Lipids of oleaginous yeasts. Part II: technology and potential applications. Eur J Lipid Sci Technol 113: 1052-1073. doi:10.1002/ejlt.201100015

Papanikolaou S, Chevalot I, Komaitis M, Aggelis G, Marc I (2001) Kinetic profile of the cellular lipid composition in an oleaginous Yarrowia lipolytica capable of producing a cocoa-butter substitute 
from industrial fats. Antonie Van Leeuwenhoek 80:215-224. doi:10. 1023/A:1013083211405

Papanikolaou S, Muniglia L, Chevalot I, Aggelis G, Marc I (2003) Accumulation of a cocoa-butter-like lipid by Yarrowia lipolytica cultivated on agro-industrial residues. Curr Microbiol 46:124-130. doi:10.1007/s00284-002-3833-3

Papaparaskevas D, Christakopoulos P, Kekos G, Macris BJ (1992) Optimizing production of extracellular lipase from Rhodotorula glutinis. Biotechnol Lett 14:397-402. doi:10.1007/BF01021254

Perrier V, Dubreucq E, Galzy P (1995) Fatty acid and carotenoid composition of Rhodotorula strains. Arch Microbiol 164:173-179. doi:10. 1007/BF02529968

Rao AV, Rao LG (2007) Carotenoids and human health. Pharmacol Res 55:207-216. doi:10.1016/j.phrs.2007.01.012

Ratledge C, Cohen Z (2008) Microbial and algal oils: do they have a future for biodiesel or as commodity oils? Lipid Technol 20:155160. doi:10.1002/lite.200800044

Ratledge C, Hall MJ (1979) Accumulation of lipid by Rhodotorula glutinis in continuous culture. Biotechnol Lett 1:115-120. doi:10. 1007/BF01386709

Rubio MC, Runco R, Navarro AR (2002) Invertase from a strain of Rhodotorula glutinis. Phytochemistry 61:605-609. doi:10.1016/ S0031-9422(02)00336-9

Saenge C, Cherisilp B, Suksaroge TT, Bourtoom T (2011a) Efficient concomitant production of lipids and carotenoids by oleaginous red yeast Rhodotorula glutinis cultured in palm oil mill effluent and application of lipids for biodiesel production. Biotechnol Bioprocess Eng 16:23-33. doi:10.1007/s12257-010-0083-2

Saenge C, Cherisilp B, Suksaroge TT, Bourtoom T (2011b) Potential use of oleaginous red yeast Rhodotorula glutinis for the bioconversion of crude glycerol from biodiesel plant to lipids and carotenoids. Process Biochem 46:210-218. doi:10.1016/j.procbio.2010.08.009

Sakaki H, Nakanishi T, Satonaka KY, Miki W, Fujita T, Komemushi S (2000) Properties of a high-torularhodin mutant of Rhodotorula glutinis cultivated under oxidative stress. J Biosci Bioeng 89:203205. doi:10.1016/S1389-1723(00)88739-3

Sakaki H, Nakanishi T, Tada A, Miki W, Komemushi S (2001) Activation of torularhodin production by Rhodotorula glutinis using weak white light irradiation. J Biosci Bioeng 92:294-297. doi:10.1016/ S1389-1723(01)80265-6

Santos CA, Caldeira ML, Lopes da Silva T, Novais JM, Reis A (2013) Enhanced lipidic algae biomass production using gas transfer from a fermentative Rhodosporidium toruloides culture to an autotrophic Chlorella protothecoides culture. Bioresour Technol 138:48-54. doi:10.1016/j.biortech.2013.03.135

Sarkissian CN, Gámez A (2005) Phenylalanine ammonia lyase, enzyme substitution therapy for phenylketonuria, where are we now? Mol Genet Metab 86:22-26. doi:10.1016/j.ymgme.2005.06.016

Schierle J, Pietsch B, Ceresa A, Fizet C, Waysek EH (2004) Method for the determination of $\beta$-carotene in supplements and raw materials by reversed phase liquid chromatography: single laboratory validation. J AOAC Int 87:1070-1081

Schneider T, Graeff-Hönninger S, French WT, Hernandez R, Merkt N, Claupein W, Hetrick M, Pham P (2013) Lipid and carotenoid production by oleaginous red yeast Rhodotorula glutinis cultivated on brewery effluents. Energy 61:34-43. doi:10.1016/j.energy.2012.12. 026

Shichang L, Pengpeng Z, Shaobin G, Hongxia L, Ya L, Shengnan L (2013) Screening of lipid high producing mutant from Rhodotorula glutinis by low ion implantation and study on optimization of fermentation medium. Indian J Microbiol 53:343-351. doi: 10.1007/s12088-013-0361-8

Sikora LA, Marzluf GA (1982) Regulation of L-phenylalanine ammonialyase by L-phenylalanine and nitrogen in Neurospora crassa. J Bacteriol 150:1287-1291
Simpson KL, Nakayama TOM, Chichester CO (1964) Biosynthesis of yeast carotenoids. J Bacteriol 88:1688-1694

Squina FM, Mercadante AZ (2005) Influence of nicotine and diphenylamine on the carotenoid composition of Rhodotorula strains. J Food Biochem 29:638-652. doi:10.1111/j.1745-4514.2005.00030.x

Suutari M, Liukkonen K, Laakso S (1990) Temperature adaptation in yeasts: the role of fatty acids. J Gen Microbiol 136:1469-1474

Takac S, Akay B, Ozdamar TH (1995) Bioconversion of trans-cinnamic acid to L-phenyloalanine ammonia lyase of Rhodotorula glutinis: parameters and kinetics. Enzym Microb Technol 17:445-452. doi: 10.1016/0141-0229(94)00072-Y

Taskin M (2013) Co-production of tannase and pectinase by free and immobilized cells of the yeast Rhodotorula glutinis MP-10 isolated from tannin-rich persimmon (Diospyros kaki L.) fruits. Bioprocess Biosyst Eng 36:165-172. doi:10.1007/s00449-012-0771-8

Taskin M, Erdal S (2010) Production of carotenoids by Rhodotorula glutinis MT-5 in submerged fermentation using the extract from waste loquat kernels as substrate. J Sci Food Agric 91:1440-1445. doi:10.1002/jsfa.4329

Taskin M, Sisman T, Erdal S, Kurbanoglu EB (2011) Use of waste chicken feathers as peptone for production of carotenoids in submerged culture of Rhodotorula glutinis MT-5. Eur Food Res Technol 233: 657-665. doi:10.1007/s00217-011-1561-2

Tinoi J, Rakariyatham N, Deming RL (2005) Simplex optimization of carotenoid production by Rhodotorula glutinis using hydrolyzed mung bean waste flour as substrate. Process Biochem 40:25512557. doi:10.1016/j.procbio.2004.11.005

Torres FAE, Zaccarim BR, de Lencastre Novaes LC, Jozala AF, Santos CA, Teixeira MF, Santos-Ebinuma VC (2016) Natural colorants from filamentous fungi. Appl Microbiol Biotechnol 100:25112521. doi:10.1007/s00253-015-7274-x

Ungureanu C, Ferdes M (2012) Evaluation of antioxidant and antimicrobial activities of torularhodin. Adv Sci Lett 5:1-4. doi:10.1166/asl. 2012.4403

Ungureanu C, Popescu S, Purcel G, Tofan V, Popescu M, Sălăgeanu A, Pîrvu C (2014) Improved antibacterial behavior of titanium surface with torularhodin-polypyrrole film. Mater Sci Eng C 42:726-733. doi:10.1016/j.msec.2014.06.020

Ungureanu C, Dumitriu C, Popescu S, Enculescu M, Tofan V, Popescu M, Pirvua C (2016) Enhancing antimicrobial activity of TiO2/Ti by torularhodin bioinspired surface modification. Bioelectrochemistry 107:14-24. doi:10.1016/j.bioelechem.2015.09.001

Wang J, Li R, Lu D, Ma S, Yan Y, Li W (2009) A quick isolation method for mutants with high lipid yield in oleaginous yeast. World $\mathrm{J}$ Microbiol Biotechnol 25:921-925. doi:10.1007/s11274-009-9960-2

Watanabe SK, Hemandez-Velazco G, Iturbe-Chinas F, Lopez-Mungia A (1992) Phenylalanine ammonia lyase from Sporidiobolus pararoseus and Rhodosporidium toruloides: application for phenylalanine and tyrosine deamination. World J Microbiol Biotechnol 8: 406-411. doi:10.1007/BF01198755

Wirth F, Goldani LZ (2012) Epidemiology of Rhodotorula: an emerging pathogen. Interdiscip Perspect Infect Dis. doi:10.1155/2012/465717

Woodside JV, McGrath AJ, Lyner N, McKinley MC (2015) Carotenoids and health in older people. Maturitas 80:63-68. doi:10.1016/j. maturitas.2014.10.012

Wu JL, Wang WY, Cheng YL, Du C, Qian H (2015) Neuroprotective effects of torularhodin against $\mathrm{H}_{2} \mathrm{O}_{2}$-induced oxidative injury and apoptosis in PC12 cells. Pharmazie 70:17-23

Xue F, Miao J, Zhang X, Luo H, Tan T (2008) Studies on lipid production by Rhodotorula glutinis fermentation using monosodium glutamate wastewater as culture medium. Bioresour Technol 99:5923-5927. doi:10.1016/j.biortech.2007.04.046

Xue F, Gao B, Zhu Y, Zhang X, Feng W, Tan T (2010) Pilot-scale production of microbial lipid using starch wastewater as raw material. Bioresour Technol 101:6092-6095. doi:10.1016/j.biortech.2010.01.124 
Yamada S, Nabe K, Izuo N, Nakamichi K, Chibata I (1981) Production of L-phenylalanine from trans-cinnamic acid with Rhodotorula glutinis containing L-phenylalanine ammonia-lyase activity. Appl Environ Microbiol 42:773-778

Yen HW, Chang JT (2014) Growth of oleaginous Rhodotorula glutinis in an internal-loop airlift bioreactor by using lignocellulosic biomass hydrolysate as the carbon source. J Biosci Bioeng 119:580-584. doi: 10.1016/j.jbiosc.2014.10.001

Yen HW, Zhang Z (2011a) Effects of dissolved oxygen level on cell growth and total lipid accumulation in the cultivation of Rhodotorula glutinis. J Biosci Bioeng 112:71-74. doi:10.1016/j. jbiosc.2011.03.013

Yen HW, Zhang Z (2011b) Enhancement of cell growth rate by light irradiation in the cultivation of Rhodotorula glutinis. Bioresour Technol 102:9279-9281. doi:10.1016/j.biortech.2011.06.062

Yen HW, Yang YC, Yu YH (2012) Using crude glycerol and thin stillage for the production of microbial lipids through the cultivation of Rhodotorula glutinis. J Biosci Bioeng 114:453-456. doi:10.1016/j. jbiosc.2012.04.022

Yu X, Zheng Y, Dorgan KM, Chen S (2011) Oil production by oleaginous yeasts using the hydrolysate from pretreatment of wheat straw with dilute sulfuric acid. Bioresour Technol 102:6134-6140. doi:10. 1016/j.biortech.2011.02.081
Zhang G, French WT, Hernandez R, Alley E, Paraschivescu M (2011) Effects of furfural and acetic acid on growth and lipid production from glucose and xylose by Rhodotorula glutinis. Biomass Bioenergy 35:734-740. doi:10.1016/j.biombioe. 2010.10.009

Zhang Z, Zhang X, Tan T (2014) Lipid and carotenoid production by Rhodotorula glutinis under irradiation/high-temperature and dark/ low-temperature cultivation. Bioresour Technol 157:149-153. doi: 10.1016/j.biortech.2014.01.039

Zhu L, Zhou L, Cui W, Liu Z, Zhou Z (2014) Mechanism-based sitedirected mutagenesis to shift the optimum $\mathrm{pH}$ of the phenylalanine ammonia-lyase from Rhodotorula glutinis JN-1. Biotechnol Rep 3: 21-26. doi:10.1016/j.btre.2014.06.001

Zlatanov M, Pavlova K, Antova G, Angelova-Romova M, Georgieva K, Rousenova-Videva S (2010) Biomass production by antarctic yeast strains: an investigation on the lipid composition. Biotechnol Biotechnol Equip 24:2096-2101. doi:10. 2478/V10133-010-0084-5

Zoz L, Carvalho JC, Soccol VT, Casagrande TC, Cardoso L (2015) Torularhodin and torulene: bioproduction, properties and prospective applications in food and cosmetics-a review. Braz Arch Biol Technol 58:278-288. doi:10.1590/ S1516-8913201400152 